\title{
Imaging Approaches to Parkinson Disease
}

\author{
David J. Brooks \\ MRC Clinical Sciences Centre and Division of Neuroscience and Mental Health, Faculty of Medicine, Imperial College, \\ Hammersmith Hospital, London, United Kingdom
}

Parkinson disease (PD) is associated with nigral degeneration and striatal dopamine deficiency. Demonstrating midbrain structural abnormalities with transcranial sonography or diffusionweighted MRI or showing striatal dopamine terminal dysfunction with PET or SPECT supports the diagnosis and rationalizes the use of dopaminergic medications. In atypical PD variants, transcranial sonography can detect striatal hyperechogenicity, and diffusion-weighted imaging can detect increased putamen water diffusion, whereas ${ }^{18} \mathrm{~F}-\mathrm{FDG}$ PET reveals reduced lentiform nucleus glucose metabolism. PET and SPECT can detect changes in striatal dopamine levels after levodopa administration and relate these to motor responses. Loss of cortical dopaminergic and cholinergic function is present in demented PD and, on occasion, amyloid deposits can be detected. Loss of cardiac sympathetic innervation can be sensitively detected in PD with ${ }^{18} \mathrm{~F}$-dopamine PET or ${ }^{123}$ I-metaiodobenzylguanidine SPECT. Finally, PET can detect widespread brain inflammation in PD. This review discusses the role of structural and functional imaging for diagnosing and managing different parkinsonian syndromes.

Key Words: PET; SPECT; magnetic resonance imaging; transcranial sonography; Parkinson's disease; dementia

J Nucl Med 2010; 51:596-609

DOI: 10.2967/jnumed.108.059998

$\mathbf{T}$ he definitive diagnosis of idiopathic Parkinson disease (PD) requires histologic demonstration of intraneuronal Lewy body inclusions in the substantia nigra compacta, and such demonstration is clearly impractical during life. The nigrostriatal projection loss that characterizes PD is associated with striatal dopamine deficiency targeting the posterior putamen. Clinicopathologic studies suggest that when established PD is diagnosed according to current U.K. Brain Bank criteria, there is a $90 \%$ concordance between expert clinical impression and the presence of nigral Lewy bodies (I).

In early $\mathrm{PD}$, however, the full triad of clinical symptoms and signs (rest tremor, bradykinesia, and rigidity) may not yet be manifested. Differential diagnoses include benign essential or dystonic tremors (2) and parkinsonism associ-

Received Sep. 26, 2009; revision accepted Nov. 16, 2009.

For correspondence or reprints contact: David J. Brooks, Imperial College London, Cyclotron Building, Hammersmith Hospital, Du Cane

Rd., London W12 ONN, U.K.

E-mail: david.brooks@csc.mrc.ac.uk

COPYRIGHT @ 2010 by the Society of Nuclear Medicine, Inc. ated with exogenous agents such as dopamine receptorblocking drugs. These conditions are not associated with nigral degeneration or striatal dopamine deficiency. In up to $15 \%$ of cases labeled as early PD by investigators, imaging has shown normal dopamine terminal function suggestive of an alternative diagnosis $(3,4)$. Given this statistic, the ability to noninvasively detect altered nigral structure or striatal dopamine terminal function potentially provides valuable tools that can help increase diagnostic specificity for dopamine-deficient parkinsonian syndromes and rationalize management decisions at initial stages of disease.

In addition, there are atypical parkinsonian disorders associated with striatal dopamine deficiency but with nonLewy body pathologies such as multiple-system atrophy, progressive supranuclear palsy, and corticobasal degeneration. The accuracy of diagnosis of these conditions improves with disease duration as their atypical features become evident, but early on they can be difficult to discriminate from idiopathic PD on clinical grounds. Vascular parkinsonism can also mimic PD, though vascular parkinsonism tends to be poorly responsive to levodopa and is characteristically associated with lower-body parkinsonism and gait apraxia.

Nonmotor complications of PD can cause greater impairment of quality of life than does the motor disability. Dementia is 2-6 times more common in PD than in agematched controls and is associated with cortical Lewy body disease and, on occasion, concomitant Alzheimer pathology. Dementia with Lewy bodies (DLB), like Alzheimer disease, is associated with impaired recall, speech, and perceptual difficulties but in addition is characterized by rigidity, fluctuating confusion, psychosis, and visual hallucinosis. Currently, it remains unclear whether DLB, PD with later dementia (PDD), and nondemented PD all represent a spectrum of Lewy body disease. Nigral degeneration is a feature of all 3 of these conditions, in contrast to Alzheimer disease, in which dopaminergic function remains intact. At postmortem examination, most cases of DLB show a mixture of cortical Lewy body inclusions and Alzheimer pathology. Functional imaging can detect the presence of dopaminergic dysfunction, cortical hypometabolism, and amyloid pathology in dementia syndromes, thus aiding their classification.

The algorithm presented in Figure 1 summarizes the role of structural and functional imaging for diagnosing and managing different parkinsonian syndromes. 


\section{IMAGING NIGRAL STRUCTURAL CHANGES}

MRI

Conventional MRI reveals brain structural changes as reductions in volume (atrophy) and alterations in waterproton relaxation $\mathrm{T} 1$ and $\mathrm{T} 2$ signals. Water normally flows along neural tracts in the brain. Diffusion-weighted or diffusion tensor MRI can be used to quantify loss of anisotropy (directionality) or increase in amplitude of water diffusion and so demonstrate disruption of neural tracts. The pathologic presence of iron in a paramagnetic chemical form reduces $\mathrm{T} 2$ relaxation times because of the increased magnetic susceptibility.

Conventional T1- and T2-weighted MRI shows normal nigral structure in idiopathic PD and so is not diagnostically helpful. Volumetric T1-weighted MRI studies have also failed to detect a reduction in nigral volume in PD, possibly because of difficulties in accurately defining the border of the nigra compacta (5). However, standard MRI sequences are valuable as they will reveal structural lesions such as basal ganglia tumors, granulomas, and calcification; vascular disease; altered basal ganglia signal due to Wilson's disease or mangan- ism/ephedrine poisoning; and hydrocephalus and allow them to be excluded as secondary causes of parkinsonism.

Inversion recovery sequences can be designed to suppress either gray or white matter signal. Segmented inversion recovery ratio imaging generates ratio images of gray matter- and white matter-suppressed signal at a voxel level. With the segmented inversion recovery ratio approach, all of an initial series of 6 PD patients were reported to show a gradient of altered nigral signal that was absent in healthy controls (6). A subsequent series from another center reported similar findings in 7 of 10 patients with established PD, suggesting a sensitivity of $70 \%$ (7). Subtraction rather than ratio images of gray matter- and white matter-suppressed signal can also be generated. With this approach, Minati et al. (8) detected significant hypointensity of the lateral nigra in PD. However, there was a $50 \%$ overlap between normal and PD nigral signal. Although the use of gray matter- and white matter-suppressing inversion recovery sequences can detect changes in nigral structures in $\mathrm{PD}$, it is a complicated approach to implement and currently not sensitive enough to be of diagnostic value.

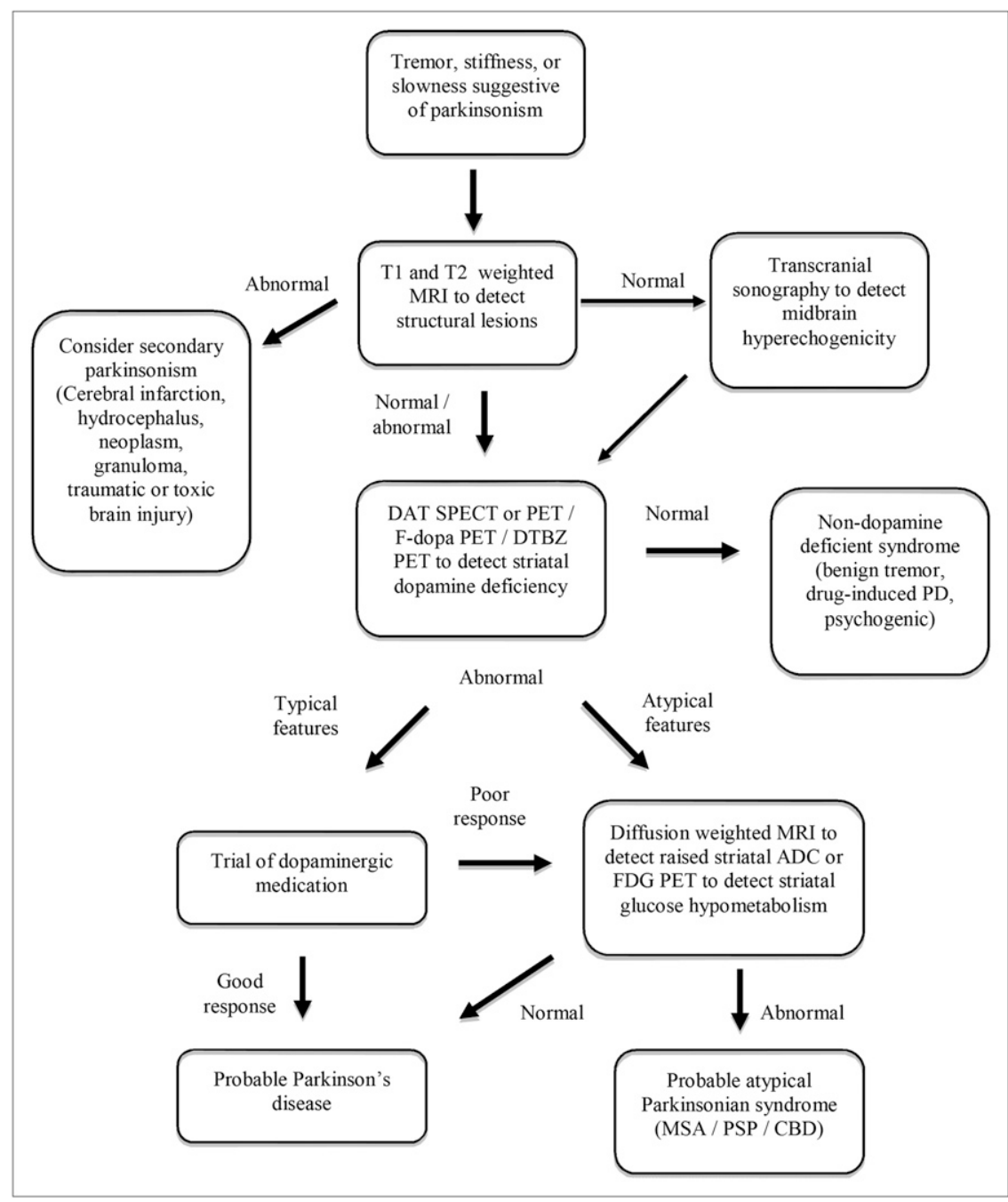

FIGURE 1. PD imaging algorithm. 
T2-weighted sequences are influenced by local increases in magnetic susceptibility when raised iron content is present in brain areas. With such an approach, Michaeli et al. (9) have been able to detect increased nigral magnetic susceptibility in PD. Again, however, midbrain relaxation times overlapped considerably with those of a healthy group.

A potential advance involves the use of diffusion tensor imaging to determine regional fractional anisotropy within the nigra. In a recent study, fractional anisotropy in the substantia nigra was measured in 14 de novo PD patients and 14 healthy volunteers matched for age and sex (10). Nigral fractional anisotropy values were reduced in all PD patients, compared with the control group (Fig. 2A). The greatest difference between the 2 groups was observed in the caudal part of the substantia nigra. These findings are in agreement with postmortem studies, which show greater cell loss in the ventrocaudal nigra than in the rostral segment of this structure. PD patients were distinguished with $100 \%$ sensitivity and specificity from the healthy volunteers on the basis of their fractional anisotropy value in the caudal nigra. If confirmed in larger cohorts of PD patients, these findings suggest that diffusion tensor imaging could be valuable for supporting a diagnosis of PD.

\section{Transcranial Sonography}

Transcranial sonography detects ultrasound echoes from brain structures. In an initial series, $92 \%$ of patients with clinically established PD were reported to show bilaterally increased echogenicity from the lateral midbrain (Fig. 2B) (11). The size of the transcranial sonography signal, however, does not correlate well with the disability rating in PD and remains static over $5 \mathrm{y}$ despite progression of symptoms (12). It has been suggested that the presence of midbrain hyperechogenicity is a trait rather than a state marker for susceptibility to parkinsonism and may reflect midbrain iron deposition (13). In support of this viewpoint, midbrain hyperechogenicity has been reported in premanifest monogenic forms of parkinsonism including carriers of $\alpha$-synuclein, lysine-rich repeat kinase (LRRK2), parkin, and DJ1 mutations $(14,15)$.

A recent prospective masked study has assessed the specificity and sensitivity of transcranial sonography for the differential diagnosis of PD (16). Sixty patients with soft signs of parkinsonism underwent baseline transcranial sonography and then were clinically assessed every 3 mo for $1 \mathrm{y}$. At the end of the follow-up period, 39 were classified as having PD, 10 as having atypical parkinsonian syndromes (which do not show midbrain hyperechogenicity), and 4 as having neither of these conditions. Compared with the final clinical diagnosis, the sensitivity of transcranial sonography for detecting PD at baseline was $91 \%$ and the specificity was $82 \%$. The positive predictive value of transcranial sonography for PD was 93\%, with an accuracy of $88 \%$.

Although these results are promising, in other recent series transcranial sonography has been reported to have sensitivities as low as $50 \%$ for clinically probable PD (17). There are also difficulties with the diagnostic use of transcranial sonography: first, increased midbrain echogenicity has also been reported in $17 \%$ of patients with essential tremor (18), $40 \%$ of depressed patients without signs of PD (19), and 10\% of age-matched healthy volunteers (11), suggesting that the specificity of transcranial sonography is suboptimal. Second, whereas $90 \%$ of subjects have a suitable preauricular acoustic bone window, in $10 \%$ no echoes can be detected. Finally, patients with severe tremor have to be excluded because movement artifacts prevent reliable interpretation of the images.
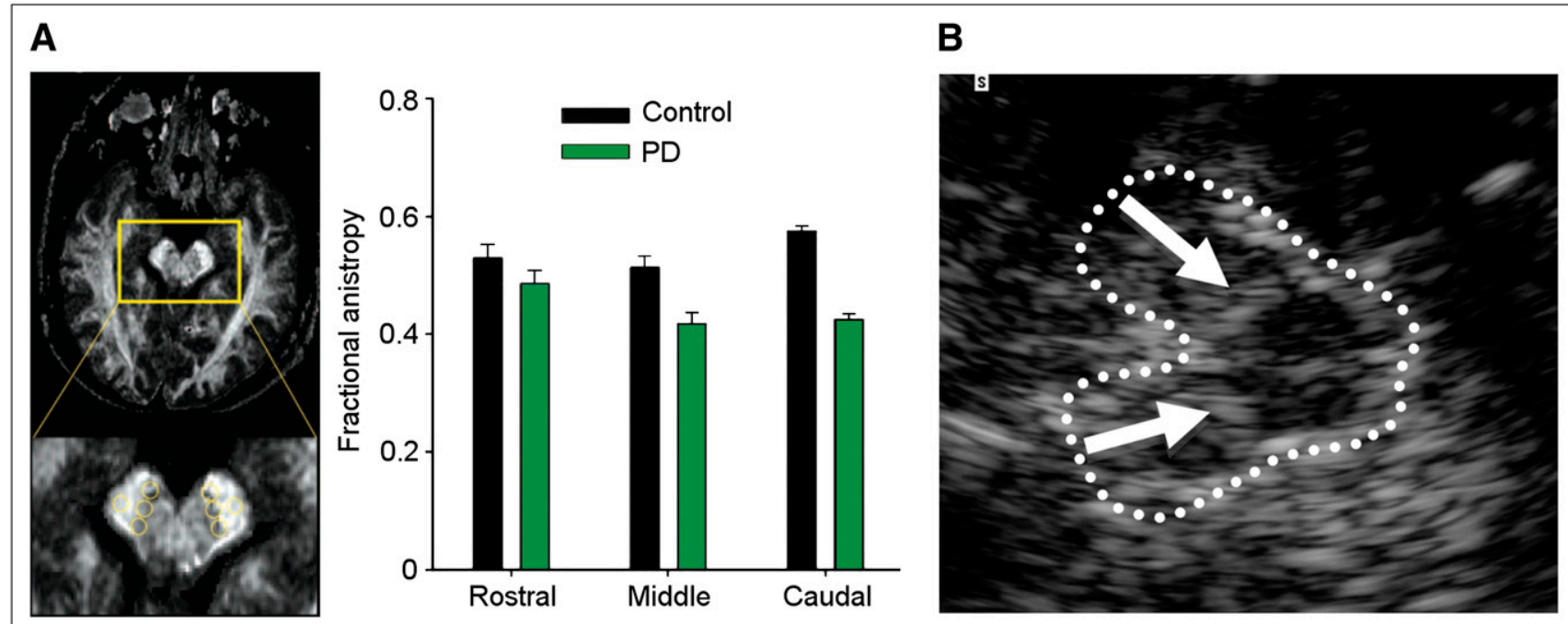

FIGURE 2. (A) Images of fractional anisotropy of midbrain. Nigral fractional anisotropy is reduced in rostral caudal gradient in PD. (Reprinted with permission of (126).) (B) Transcranial sonography showing hyperechogenicity from lateral midbrain (substantia nigra) in PD. (Reprinted with permission of (11).) 


\section{IMAGING STRUCTURAL CHANGE IN ATYPICAL PD}

MRI can play a valuable role in discriminating atypical parkinsonian syndromes, such as multiple-system atrophy and progressive supranuclear palsy, from typical PD. Atrophy of the lentiform nucleus is a feature of these atypical disorders, but volumetric MRI has not proved sensitive enough to be of diagnostic value $(20,21)$. In contrast, diffusion-weighted and diffusion tensor MRI is highly sensitive to changes in striatal structure and potentially useful for discriminating atypical from typical parkinsonian disorders. Diffusion-weighted MRI has been reported to detect raised water-proton apparent diffusion coefficients in the putamen in $90 \%-100 \%$ of patients with clinically probable multiple-system atrophy and progressive supranuclear palsy, whereas apparent diffusion coefficients in the putamen are normal in PD (Fig. 3) (22-24). Multiplesystem atrophy can be discriminated from progressive supranuclear palsy by the presence of an altered water diffusion signal in the middle cerebral peduncle (25). These studies have all involved well-established atypical cases, however, and it remains to be seen how well diffusion-weighted MRI will perform with early gray cases in prospective series where clinical diagnostic uncertainty is still present.

Interestingly, although nigral degeneration is a feature of both typical and atypical parkinsonian syndromes, transcranial sonography does not detect midbrain hyperechogenicity in atypical PD. Increased echogenicity of the lentiform nucleus is, however, present in most of these cases and absent in typical PD (26). A combination of normal midbrain signal combined with lentiform nucleus hyperechogenicity separated atypical from typical PD with a sensitivity of 59\% and specificity of $100 \%$ and a positive predictive value of $100 \%$.

\section{IMAGING PRESYNAPTIC DOPAMINERGIC FUNCTION IN PD}

The function of dopamine terminals in PD can be examined in vivo in 3 main ways (27). First, the availability of presynaptic dopamine transporters (DAT) can be assessed with a variety of PET and SPECT tracers, most of which are tropane-based. Examples include ${ }^{123} \mathrm{I}-(-)-2 \beta-$ carbomethoxy-3 $\beta$-(4-iodophenyl)tropane $\quad\left({ }^{123} \mathrm{I}-\beta\right.$-CIT) (Dopascan; Guilford Pharmaceuticals Inc.), ${ }^{123} \mathrm{I}-\mathrm{N}-3-$ fluoropropyl-2 $\beta$-carbomethoxy-3 $\beta$-(4-iodophenyl)tropane ( ${ }^{123} \mathrm{I}$-FP-CIT) (DaTSCAN; GE Healthcare), ${ }^{123} \mathrm{I}$-altropane, and ${ }^{11} \mathrm{C}-2$-carbomethoxy-3-(4- ${ }^{18} \mathrm{~F}$-fluorophenyl)tropane $\left({ }^{11} \mathrm{C}-\mathrm{CFT}\right)$. Second, ${ }^{18} \mathrm{~F}-3,4-d i h y d r o x y p h e n y l a l a n i n e ~\left({ }^{18} \mathrm{~F}-\mathrm{dopa}\right)$ PET provides a marker of terminal dopa decarboxylase activity and dopamine turnover. Third, vesicle monoamine transporter availability in dopamine terminals can be examined with either ${ }^{11} \mathrm{C}$ - or ${ }^{18} \mathrm{~F}$-dihydrotetrabenazine PET. Early hemiparkinsonian patients show bilaterally reduced putamen dopaminergic terminal function, activity being more depressed in the posterior putamen contralateral to the affected limbs (Fig. 4) $(28,29)$. Head-of-caudate and ventral striatal function is relatively preserved. Clinical parkinsonism occurs when PD patients have lost 40\%-50\% of posterior putamen dopamine terminal function $(30,31)$. Levels of putamen ${ }^{18} \mathrm{~F}$-dopa uptake and DAT binding correlate inversely with bradykinesia and rigidity of PD patients, but interestingly, not with tremor severity (32-34). This suggests that parkinsonian tremor is not a direct consequence of nigrostriatal degeneration.

Not all dopamine fibers are damaged in early PD—some increase their dopamine turnover as an adaptive mechanism. At the onset of rigidity and bradykinesia, globus pallidus interna ${ }^{18} \mathrm{~F}$-dopa uptake is increased by up to $50 \%$ (35). As the disease advances, pallidal ${ }^{18} \mathrm{~F}$-dopa storage then falls, eventually becoming subnormal. Disability is then severe and treatment complications develop. This observation suggests that both the putamen and the globus pallidus interna require an intact dopaminergic input from the nigra if limb movements are to be fluent and efficient, and it is when both sets of projections are damaged that the honeymoon period in PD reaches an end.

When clinically probable PD and essential tremor patients have been compared, striatal DAT imaging with ${ }^{123}$ I-FP-CIT SPECT has been shown to differentiate these conditions with a sensitivity and specificity of over $90 \%$ (36). Several studies have examined the role of DAT imaging for determining whether gray parkinsonian cases are associated with striatal dopamine deficiency. In the Query PD study, the standard of truth was the clinical impression of 2 movement disorder experts after 6 mo of clinical follow-up (37). Although referring clinicians showed $92 \%$ sensitivity for diagnosing dopamine-deficient parkinsonism, their baseline clinical specificity was poor
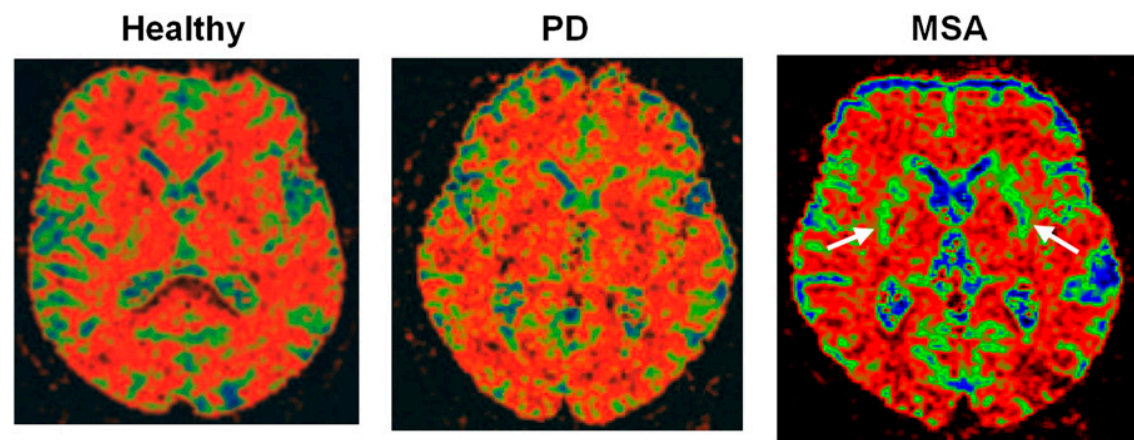

FIGURE 3. Color-coded diffusionweighted MR images of healthy subject, patient with PD, and patient with atypical parkinsonian syndrome multiplesystem atrophy. Apparent diffusion coefficient is normal in striatum of PD patient but raised in multiple-system atrophy because of neuronal loss that targets putamen. MSA = multiple-system atrophy. (Reprinted with permission of (22).) 
Normal
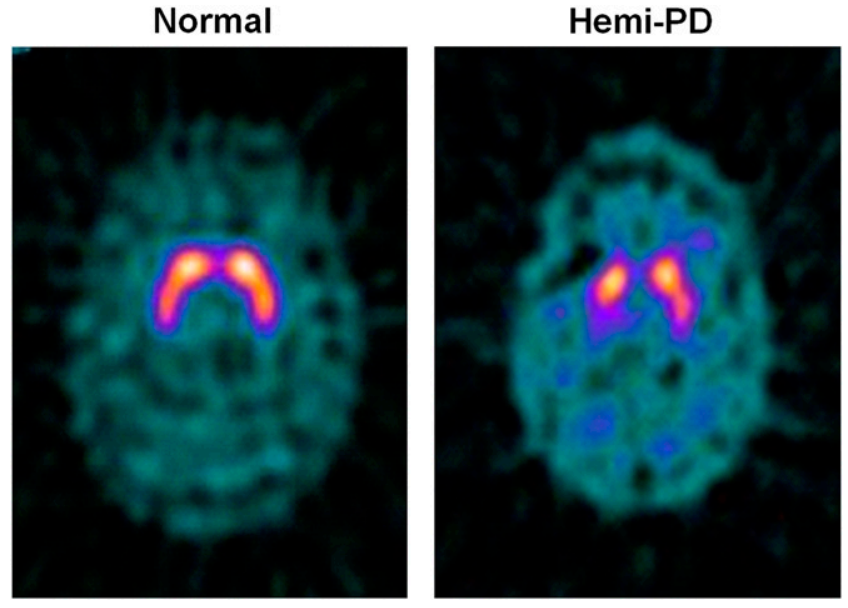

FIGURE 4. ${ }^{123}$ I-FP-CIT SPECT images of healthy volunteer and patient with early hemi-PD. PD patient shows asymmetric bilateral loss of putamen DAT binding. (Courtesy of Donald Grossett.)

(30\%) compared with the standard of truth whereas baseline imaging specificity with ${ }^{123} \mathrm{I}-\beta$-CIT SPECT was $100 \%$. These findings suggest that clinicians tend to overcall a diagnosis of PD in gray cases.

A similar conclusion was reached by investigators participating in a European multicenter, prospective, longitudinal study in which clinical diagnosis was compared with ${ }^{123}$ I-FP-CIT SPECT findings (38). Serial observations were performed over $3 \mathrm{y}$ on patients in whom there was initial diagnostic uncertainty between degenerative parkinsonism and a benign tremor disorder. The standard of truth was examination of videos of the clinical features at $36 \mathrm{mo}$ by 2 movement disorder experts who were not aware of the imaging results. Three readers, unaware of the clinical diagnosis, classified ${ }^{123}$ I-FP-CIT SPECT findings as normal or abnormal by visual inspection. In 99 patients who completed the 36-mo trial, on-site baseline clinical diagnosis, compared with the standard of truth, had a sensitivity of $93 \%$ but a specificity of only $46 \%$. Baseline ${ }^{123}$ I-FP-CIT SPECT showed a mean sensitivity of $78 \%$ and a specificity of $97 \%$, again implying that a diagnosis of PD was overcalled in around $15 \%$ of subjects.

The "Impact of Dopamine Transporter SPECT on the Diagnosis and Management of Patients with Clinically Uncertain Parkinsonian Syndromes" (CUPS) trial was designed to establish whether a knowledge of baseline striatal DAT binding influenced subsequent management (39). When FP-CIT SPECT findings were divulged to clinicians, the diagnosis of dopamine-deficient parkinsonian syndrome was revised in $52 \%$ of the 118 patients and the management strategy was changed in $72 \%$ of patients. A 2 -y follow-up found that $90 \%$ of subjects still retained the diagnosis assigned after clinicians were made aware of baseline FPCIT SPECT findings (40). These studies support the view that including a measure of striatal dopaminergic function in the work-up of gray parkinsonian cases helps in planning their management. However, a problem with the CUPS study is that because no nonimaged control group was included, one cannot be sure that knowledge of DAT binding at baseline led to improved patient outcome. Additionally, the pathology of these patients still remains unclear as clinical follow-up was the standard of truth.

Up to $15 \%$ of early cases suspected of representing dopamine-deficient parkinsonian syndrome showed normal dopamine terminal function on PET or SPECT $(3,4)$. The prognostic value of this finding remains uncertain, but a series by Marshall et al. has helped to throw light on this (41). One hundred fifty patients with possible early parkinsonism but normal FP-CIT SPECT findings were followed up for 2 y. Only 4 (3\%) of these patients showed clinical progression and were still believed to have PD 2 y later; the rest were labeled as having either benign tremulous or nondegenerative parkinsonian disorders. These findings imply that a SPECT or PET finding of normal presynaptic dopaminergic function in a case of suspected PD is associated with a good prognosis whatever the ultimate diagnosis.

One of the more common causes of confusion with PD is an adult-onset dystonic tremor, which can present as an asymmetric resting arm tremor with impaired arm swing but without evidence of true akinesia (2). In these patients, functional imaging should be considered to avoid inappropriate medication with dopaminergic agents. Marshall et al. presented 11 patients who initially fulfilled diagnostic criteria for PD and were treated with dopaminergic agents but in whom emerging diagnostic doubts led to DAT imaging with FP-CIT SPECT - which had negative results-and subsequent antiparkinsonian therapy withdrawal (42). Withdrawal was achieved without clinical deterioration, suggesting that dopaminergic imaging can be valuable when inappropriate use of antiparkinsonian medication is suspected.

\section{REGIONAL CEREBRAL GLUCOSE METABOLISM AND PD}

${ }^{18}$ F-FDG PET can be used to assess levels of resting regional cerebral glucose metabolism. Absolute levels in the lentiform nucleus lie within the reference range in PD (43); however, covariance analysis reveals an abnormal profile of relatively raised resting lentiform nucleus and lowered frontal and parietotemporal metabolism (44). The degree of expression of this PD-related profile correlates with clinical disease severity, thus providing a potential biomarker of disease progression. Successful treatment with levodopa or deep brain stimulation reduces expression of the PDrelated profile $(45,46)$. Given this, changes in treatment could result in a potential confounding factor if ${ }^{18} \mathrm{~F}-\mathrm{FDG}$ PET were to be used as a biomarker to follow PD progression.

Eckert et al. performed ${ }^{18}$ F-FDG PET on 8 patients with suspected early parkinsonism but normal findings on ${ }^{18} \mathrm{~F}$ dopa PET (47). None of these 8 patients expressed a PDrelated profile of glucose metabolism, and over 3 y none of 
them showed any clinical progression of their disorder. This finding reinforces the viewpoint that normal dopaminergic imaging excludes the presence of a degenerative parkinsonian syndrome.

\section{FUNCTIONAL IMAGING AND ATYPICAL PD}

Imaging presynaptic dopaminergic terminal function with either striatal ${ }^{18} \mathrm{~F}$-dopa uptake or a DAT SPECT marker shows high sensitivity for detecting atypical parkinsonian syndromes but only poor specificity for discriminating them from typical PD $(48,49)$. The typical gradient of loss of dopaminergic function in PD, where the head of the caudate is relatively spared, is less evident in progressive supranuclear palsy and corticobasal degeneration patients $(48,50,51)$. In progressive supranuclear palsy, there is a more symmetric pattern of nigrostriatal dysfunction than in other parkinsonian syndromes.

In contrast, measurements of resting glucose metabolism can be helpful for separating typical from atypical parkinsonian syndromes. In typical idiopathic PD, lentiform nucleus glucose metabolism is preserved or raised, whereas it is reduced in most atypical cases (Fig. 5) (43,52-54).

\section{DETECTION OF PRECLINICAL PD}

For every patient who presents with clinical PD there may be 10 subclinical cases with incidental brain stem Lewy body disease in the community (55). Subjects at risk of developing PD include carriers of genetic mutations known to be associated with parkinsonism ( $\alpha$-synuclein, parkin, LRRK2, glucocerebrosidase A), relatives of patients with the disorder, elderly subjects with idiopathic hyposmia, and patients with rapid-eye-movement sleep behavior disorders.

When asymptomatic adult relatives in kindreds with familial PD are studied, $25 \%$ show reduced levels of putamen ${ }^{18} \mathrm{~F}$-dopa uptake and one third of these subsequently develop clinical parkinsonism (56). Parkin gene mutations are the most commonly known cause of youngonset recessive parkinsonism. Parkin is a ubiquitin ligase, and many mutations of the gene have been described. Most clinically affected cases are compound heterozygote gene carriers (a different mutation on the 2 chromosome 6s) rather than homozygous for the same mutation. Clinically affected compound heterozygote gene carriers show severe reductions of striatal ${ }^{18} \mathrm{~F}$-dopa uptake even when disability is mild, suggesting that adaptive processes develop to compensate for their dopamine deficiency $(57,58)$. The pattern of dopaminergic deficit in symptomatic parkin patients mimics that of idiopathic PD, putamen being targeted, but the caudate and midbrain are relatively more involved (59). Asymptomatic heterozygote parkin gene carriers also show a mild but significant reduction in putamen ${ }^{18} \mathrm{~F}$-dopa uptake (60). This dopaminergic deficit could conceivably make heterozygote carriers more susceptible to late-onset PD.
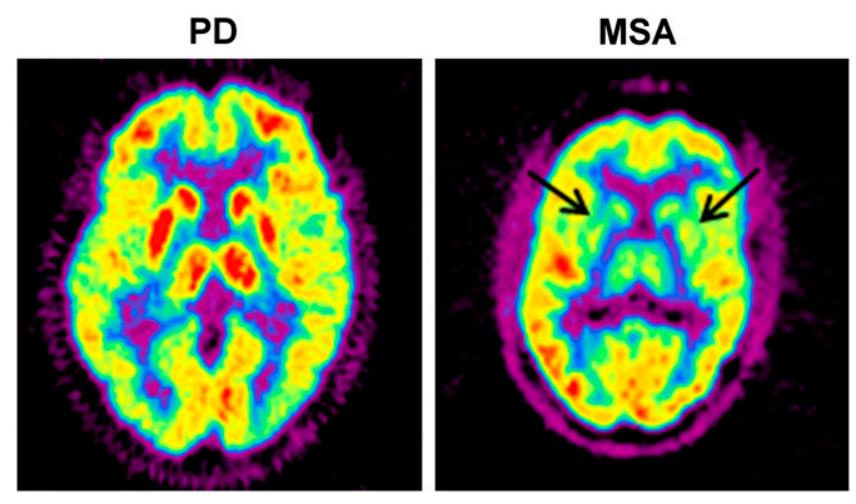

FIGURE 5. ${ }^{18}$ F-FDG PET images of PD and multiplesystem atrophy patient. Multiple-system atrophy patient shows significant striatal reduction of glucose metabolism. MSA = multiple-system atrophy.

Mutations of the LRRK2 gene-PARK8-are the most commonly known cause of later-onset dominantly inherited PD. Adams et al. have used ${ }^{18} \mathrm{~F}$-dopa, ${ }^{11} \mathrm{C}$-dihydrotetrabenazine, and ${ }^{11} \mathrm{C}$-methylphenidate PET to assess the striatal dopamine storage capacity, vesicular monoamine transporter binding, and DAT binding in 15 family members of a LRRK2 kindred (61). The 4 clinically affected LRRK2 members studied had imaging findings similar to idiopathic PD: loss of dopaminergic function targeting the putamen. Two asymptomatic mutation carriers showed reduced putamen ${ }^{11} \mathrm{C}$-methylphenidate but normal ${ }^{18} \mathrm{~F}$-dopa uptake suggesting a selective reduction of DAT binding. This finding is in line with findings in idiopathic PD, in which putamen DAT binding is known to be relatively more depressed than ${ }^{18}$ F-dopa uptake (62). Another 2 asymptomatic mutation carriers had DAT binding that was normal at baseline but subsequently fell over $4 \mathrm{y}$ of follow-up while ${ }^{18} \mathrm{~F}$-dopa uptake remained normal. The authors concluded that the neurochemical phenotype of LRRK2 mutations was indistinguishable from that of sporadic PD. Asymptomatic gene carriers, however, can show downregulation of DAT binding and preservation of dopa decarboxylase activity, which will act to maintain levels of synaptic dopamine and delay the onset of parkinsonism.

Relatives of PD patients with idiopathic hyposmia are at risk of PD. Ponsen et al. collected 40 such relatives after screening 400 subjects for hyposmia and, with ${ }^{123}$ I- $\beta$-CIT SPECT, found that 7 of these showed reduced striatal DAT binding (63). Four of these 7 subsequently converted to clinical PD over a 2-y period.

Patients with idiopathic rapid-eye-movement sleep behavior disorder are at high risk of developing parkinsonism or dementia. Using ${ }^{123}$ I-IPT SPECT, Eisensehr et al. found reduced striatal DAT binding in all 5 of their patients with idiopathic rapid-eye-movement sleep behavior disorder (64). In another series, 11 patients with sleep disorders were investigated with FP-CIT SPECT, and reduced striatal DAT binding was found in 3, 1 of whom had evidence of clinical parkinsonism (65). 
Increased midbrain echogenicity has been reported in 5 of 7 asymptomatic parkin gene carriers (14) and 11 of 30 idiopathic hyposmic patients (66). Three of the 5 parkin carriers with abnormal transcranial sonography findings showed reduced striatal ${ }^{18} \mathrm{~F}$-dopa uptake, whereas 5 of the 11 hyposmic patients had reduced striatal FP-CIT binding. Midbrain hyperechogenicity detected by ultrasound in atrisk subjects, therefore, is associated with dopamine cell dysfunction in around half of the subjects. A study from 2006 reported no correlation between levels of midbrain hyperechogenicity in PD and reductions in striatal DAT binding measured with ${ }^{99 m}$ TRODAT SPECT. This finding again suggests that transcranial sonography is detecting nondopaminergic pathology present in PD such as midbrain iron deposition (67).

\section{MECHANISMS UNDERLYING FLUCTUATIONS AND DYSKINESIAS}

PD patients show reduced putamen ${ }^{18} \mathrm{~F}$-dopa uptake whether they have sustained or fluctuating motor responses to levodopa, but mean uptake is $20 \%$ lower in the latter group (68). There is, however, considerable overlap of individual levels of putamen ${ }^{18} \mathrm{~F}$-dopa uptake in fluctuator and nonfluctuator cohorts, and so, loss of putamen dopamine terminal function cannot be the sole factor responsible for determining the timing of onset of motor complications.

${ }^{11} \mathrm{C}$-raclopride PET studies have reported that putamen $\mathrm{D}_{2}$ binding is initially increased by up to $20 \%$ in de novo PD but that after 6 mo of treatment with levodopa, $\mathrm{D}_{2}$ receptor availability returns to normal $(69,70) .{ }^{11} \mathrm{C}-\mathrm{SCH} 23390 \mathrm{PET}$ reveals normal striatal $\mathrm{D}_{1}$ binding in de novo $\mathrm{PD}$, whereas patients chronically exposed to levodopa show a $20 \%$ reduction (71). Striatal dopamine $\mathrm{D}_{1}$ and $\mathrm{D}_{2}$ receptor availability has been compared in dyskinetic and nondyskinetic groups of PD patients with similar clinical disease duration and severity who were receiving a similar daily dose of levodopa (71). Similar levels of $\mathrm{D}_{1}$ and $\mathrm{D}_{2}$ receptor binding were found, suggesting that onset of motor fluctuations and dyskinesias in PD is not driven by alterations in striatal postsynaptic dopamine receptor availability.

${ }^{11} \mathrm{C}$-raclopride PET is able to indirectly detect synaptic dopamine fluxes by monitoring changes in striatal $\mathrm{D}_{2}$ receptor availability (72). The higher the extracellular dopamine level, the lower the dopamine $\mathrm{D}_{2}$ site availability to the tracer. Animal microdialysis studies suggest that a $25 \%$ fall in putamen ${ }^{11} \mathrm{C}$-raclopride uptake after amphetamine equates to a 10-fold rise in synaptic dopamine levels (73). When PD patients are given levodopa treatment they show a fall in striatal ${ }^{11} \mathrm{C}$-raclopride binding. Pavese et al. have reported that the response of bradykinesia and rigidity to levodopa in PD correlates with the resulting increases in striatal dopamine levels detected with ${ }^{11} \mathrm{C}$-raclopride PET (74). The fall in striatal ${ }^{11} \mathrm{C}$-raclopride binding after levodopa is greater in the putamen of advanced-PD patients with fluctuations than in early cases, implying that higher levels of synaptic dopamine are generated by the former (75). This reflects the compensatory increase in dopamine turnover in remaining dopamine terminals in advanced fluctuators and their failure to buffer the dopamine generated from exogenous levodopa because of the loss of DATs and vesicles.

The failure to buffer dopamine levels by the striatum in advanced PD results in high nonphysiologic swings in synaptic dopamine levels. This, in turn, promotes excessive dopamine receptor internalization into neurons, the normal mechanism for dissociating dopamine from the receptor, leading to fluctuating and unpredictable treatment responses. In support of this viewpoint, De la FuenteFernandez et al. (76) have measured striatal ${ }^{11} \mathrm{C}$-raclopride binding in PD at 1 and $4 \mathrm{~h}$ after oral levodopa challenges. These workers found that fluctuators showed transient 8 -fold rises in synaptic dopamine levels whereas sustained responders generated only 2 -fold rises, which then slowly further increased over the next $4 \mathrm{~h}$. It is this phenomenon, rather than changes in postsynaptic dopamine $D_{1}$ and $D_{2}$ receptor availability, that results in the more rapid but shortlived response of advanced PD patients to oral levodopa. These workers also noted that "off" episodes could coincide with apparently adequate synaptic dopamine levels, again supporting the concept that excessive receptor internalization could lead to unpredictable nonavailability of dopamine binding sites at times.

In their ${ }^{11} \mathrm{C}$-raclopride PET study, Pavese et al. noted that the severity of peak-dose dyskinesias generated by levodopa administration in advanced-PD patients correlated with striatal levels of dopamine generated (74). This finding implies that overstimulation of dopamine receptors is a major factor in generating peak-dose dyskinesias. However, studies on animal lesion models of PD have shown that changes in peptide transmission also play an important role (77). Medium spiny neurons in the caudate and putamen project to the external and internal pallidum, where, along with $\gamma$-aminobutyric acid, they release enkephalin, dynorphin, and substance $\mathrm{P}$ (globus pallidus interna). Enkephalin binds mainly to $\delta$-opioid sites and inhibits $\gamma$-aminobutyric acid release in the enkephalin. Dynorphin binds to $\mathrm{\kappa}$-opioid sites and inhibits glutamate release in the globus pallidus interna from subthalamic projections. The caudate and putamen contain high densities of $\mu-, \kappa_{-}$, and $\delta$-opioid sites and also neurokinin 1 sites, which bind substance P. Opioid receptors are located both presynaptically on dopamine terminals, where they regulate dopamine release, and postsynaptically on interneurons and medium spiny projection neurons.

${ }^{11} \mathrm{C}$-diprenorphine PET is a nonselective marker of $\mu$-, $\kappa-$, and $\delta$-opioid sites, and its binding is sensitive to levels of endogenous opioids. Significant reductions in ${ }^{11} \mathrm{C}$ diprenorphine binding in caudate, putamen, thalamus, and anterior cingulate have been reported in dyskinetic patients, compared with sustained responders (78). Individual levels of putamen ${ }^{11} \mathrm{C}$-diprenorphine uptake correlated inversely 
with the severity of dyskinesia. These findings are compatible with the presence of raised basal ganglia levels of enkephalin and dynorphin in these dyskinetic PD patients. ${ }^{18}$ F-SPARQ PET is a selective marker of neurokinin 1 site availability. In a preliminary study, thalamic neurokinin 1 availability has been shown to be reduced in dyskinetic PD patients but normal in nondyskinetic patients (79). These in vivo PET findings support the abnormal presence of elevated levels of endogenous peptides in the basal ganglia of dyskinetic PD patients.

\section{IMAGING THE PHARMACOLOGY OF DEPRESSION IN PD}

The prevalence of depression in PD has been reported to range from $10 \%$ to $45 \%$ (80). Because Lewy body pathology is known to affect serotonergic and noradrenergic as well as dopaminergic neurotransmission, dysfunction of any or all of these systems would seem to be a reasonable candidate for the functional substrate of depression (81). To date, functional imaging has failed to demonstrate a correlation between serotonergic dysfunction and depression in PD.

${ }^{123}$ I- $\beta$-CIT binds with nanomolar affinity to dopamine, noradrenaline, and serotonin transporters. Although striatal uptake of ${ }^{123} \mathrm{I}-\beta$-CIT $24 \mathrm{~h}$ after intravenous injection primarily reflects DAT binding, midbrain uptake $1 \mathrm{~h}$ after administration reflects serotonin transporter availability (82). Kim et al. have reported normal brain stem ${ }^{123} \mathrm{I}-$ $\beta$-CIT uptake in PD. They found no difference between uptake in depressed and nondepressed patients and no correlation between radiotracer uptake and Hamilton Depression Rating Scale scores (83).

The serotonin 5-hydroxytryptamine receptor $1 \mathrm{~A}\left(5-\mathrm{HT}_{1 \mathrm{~A}}\right)$ is found as an autoreceptor on 5-HT cell bodies in the midbrain raphe nuclei, where it acts to inhibit serotonin release, and also postsynaptically on cortical pyramidal neurons. ${ }^{11} \mathrm{C}$-WAY $100635 \mathrm{PET}$ is an in vivo marker of $\mathrm{HT}_{1 \mathrm{~A}}$ sites, and PD patients show a $25 \%$ reduction of $\mathrm{HT}_{1 \mathrm{~A}}$ binding in the midbrain raphe, compared with healthy controls. However, the level of reduction is similar in PD patients whether a history of depression features or not (84). The results from these ${ }^{11} \mathrm{C}-\mathrm{WAY} 100635$ PET and ${ }^{123} \mathrm{I}-\beta-\mathrm{CIT}$ SPECT studies, therefore, are in agreement and do not support the view that serotonergic loss contributes to depression in PD. They also provide no rationale for the use of selective serotonin reuptake inhibitors to treat PD depression.

${ }^{11} \mathrm{C}$-methyl (1R-2-exo-3-exo)-8-methyl-3-(4-methylphenyl)8-azabicyclo[3.2.1] octane-2-carboxylate ( ${ }^{11} \mathrm{C}$-RTI 32) PET is a marker of DAT and noradrenaline transporter binding. Nondepressed PD patients show reduced putamen ${ }^{11} \mathrm{C}$-RTI 32 uptake, but patients with a history of depression show additional reductions of ${ }^{11} \mathrm{C}$-RTI 32 binding in the noradrenergic locus coeruleus, the thalamus, and the limbic system (amygdala, ventral striatum, and anterior cingulate) (85). Severity of anxiety inversely correlates with ${ }^{11} \mathrm{C}$-RTI 32 binding in these regions. These results suggest that depression and anxiety in PD are associated with loss of noradrenergic and limbic dopaminergic innervation additional to the striatal dopamine deficiency present. The use of nonselective inhibitors of monoamine transporters boosting synaptic levels of dopamine and noradrenaline would, therefore, seem a rational approach for treating depression in PD rather than the use of selective serotonin reuptake inhibitors.

\section{TREATMENT-RELATED IMPULSE CONTROL DISORDERS}

When PD patients are exposed to dopaminergic medication-particularly agonists - a small minority develop impulse control disorders such as pathologic gambling and hypersexuality in the absence of any previous history. Impulse control disorders can devastate the quality of life of PD patients and their families; affected patients have gambled away their life savings before the problem has come to light. The mechanisms underlying the development of these behavioral disturbances in PD are currently under extensive investigation.

Using 99m Tc-ethylcysteinate dimer bicisate SPECT, a marker of regional cerebral blood flow, it has been reported that $\mathrm{PD}$ patients with pathologic gambling show resting overactivity of a right hemisphere network involved in reward processing that includes the orbitofrontal cortex, hippocampus, amygdala, insula, and ventral pallidum (86). PD patients with pathologic gambling have also been studied with ${ }^{11} \mathrm{C}$-raclopride PET during performance of a gambling task. The pathologic gamblers demonstrated greater decreases in ventral striatum $\mathrm{D}_{2}$ binding during gambling $(13.9 \%)$ than control patients $(8.1 \%)$, providing supportive evidence that excessive limbic dopaminergic stimulation underlies the neurobiology of impulse control disorders in PD (87).

\section{MECHANISMS UNDERLYING DEMENTIA IN PD}

The overall prevalence of dementia is around $40 \%$ in patients with PD across different series, and the incidence is 6 times higher than that in age-matched healthy people, increasing with age (88). If PD patients live for $20 \mathrm{y}$, around $80 \%$ develop this complication (89). Factors contributing to the cognitive dysfunction include direct involvement of the cortex by Lewy body pathology, loss of cholinergic projections from the nucleus basalis of Meynert, degeneration of mesofrontal and mesolimbic dopaminergic projections, coexistent Alzheimer disease, and small-vessel pathology. The presence of these various contributors can be detected with a combination of structural and functional imaging.

\section{MRI Volumetry}

Voxel-based morphometry can be applied to volumetric MRI to localize significant regional brain volume reductions in patients at a voxel level. When PDD patients are studied with voxel-based morphometry, significant hippocampal, thalamic, and anterior cingulate atrophy can be detected (90). Sub- 
clinical volume loss in these areas can also be detected in nondemented PD patients. As PDD progresses, a further volume loss occurs from cortical association areas (91). The boundary-shift integral approach applied to volumetric MRI allows whole-brain volume changes to be quantitated. With this approach, Burton et al. computed a $0.31 \%$ annual loss of brain volume in PD (similar to healthy elderly individuals), whereas in PDD the annual loss was $1.12 \%$, approaching the $2 \%$ reported for Alzheimer disease (92). These workers concluded that MRI may provide a useful tool for following progression of $\mathrm{PD}$ with dementia.

\section{Metabolic Imaging}

In PD patients who develop dementia, ${ }^{18}$ F-FDG PET has demonstrated a characteristic pattern of reduced resting regional cerebral glucose metabolism targeting the posterior cingulate, parietal, and temporal association regions, with lesser involvement of the prefrontal cortex $(93,94)$. Primary motor and visual areas and the basal ganglia are spared. This pattern of reduced glucose metabolism is similar to that reported in Alzheimer disease (95), suggesting that Lewy body and Alzheimer pathology are associated with overlapping patterns of cortical neuronal dysfunction. Temporoparietal cortical hypometabolism can also be observed in a minority of nondemented PD patients with established disease, suggesting that subclinical cortical Lewy body involvement may already be present (96). It remains to be determined whether the observed glucose hypometabolism in these subjects is a predictor of late-onset dementia. DLB is characterized by onset of dementia associated with a combination of parkinsonism, visual hallucinations, psychosis, and fluctuating confusion. Again, the pattern of reduced ${ }^{18} \mathrm{~F}$-FDG uptake resembles that seen in Alzheimer disease, though more severe involvement of the occipital cortex has been reported (97).

\section{Dopaminergic Imaging}

Although Lewy body pathology targets the substantia nigra, this nucleus is spared in Alzheimer disease. In an initial series, Walker et al. (98) assessed the integrity of nigrostriatal function by measuring DAT binding with ${ }^{123}$ IFP-CIT SPECT in patients with PD, Alzheimer disease, and DLB. They reported, as would be expected, that PD and DLB patients had significantly reduced striatal uptake of ${ }^{123}$ I-FP-CIT, whereas this uptake was normal in Alzheimer disease (Fig. 6). Autopsy data subsequently became available for 10 of the dementia subjects investigated with SPECT. All 4 subjects proven to have DLB at postmortem examination showed reduced striatal ${ }^{123}$ I-FP-CIT uptake. Four of 5 autopsy-proven Alzheimer patients showed normal striatal ${ }^{123}$ I-FP-CIT uptake, whereas the fifth, who had been diagnosed with DLB in life, had concomitant small-vessel disease and showed reduced DAT binding. ${ }^{123}$ I-FP-CIT SPECT, therefore, provided a sensitivity of $100 \%$ and a specificity of $83 \%$ for separation of DLB from Alzheimer disease. This result compares favorably with the clinical impression, which diagnosed only 4 of the 9 cases of DLB correctly in life.

In a follow-up series gathered over $10 \mathrm{y}$, these workers reported correlations between clinical impression, pathology, and striatal ${ }^{123}$ I-FP-CIT uptake in 20 dementia patients (8 had pathologically proven DLB; 9 had Alzheimer pathology, often with coexisting cerebrovascular disease; and 3 had other diagnoses-frontotemporal dementia, corticobasal degeneration, or nonspecific pathology) (99). Using pathology as the standard of truth, Walker et al. found that an initial diagnosis of DLB based on clinical consensus criteria had a sensitivity of $75 \%$ and a specificity of $42 \%$. In contrast, the baseline sensitivity of ${ }^{123}$ I-FP-CIT SPECT for making a diagnosis of DLB was $88 \%$ and the specificity was $100 \%$.

Parallel results have emerged from a longitudinal clinical study of 44 individuals labeled as having possible DLB who all had undergone baseline ${ }^{123}$ I-FP-CIT SPECT (100). A consensus panel, unaware of baseline SPECT findings, assigned a clinical diagnosis after 12 mo of follow-up, and this diagnosis was used as the standard of truth. Nineteen of the 44 possible cases of DLB were diagnosed as probable DLB after follow-up, and 12 of these had abnormal ${ }^{123}$ I-FPCIT SPECT findings at baseline (sensitivity, 63\%). Seven of the 44 possible cases of DLB were reclassified as Alzheimer disease at follow-up, and all had normal DAT binding at baseline (specificity, 100\%). These workers concluded that DAT imaging had a useful supportive role in classifying uncertain dementia cases.

${ }^{123}$ I-FP-CIT SPECT has been used to assess the relative extent and pattern of striatal DAT loss in patients with DLB, compared with PDD patients (101). Striatal ${ }^{123}$ I-FPCIT uptake was reduced by a similar magnitude in DLB, PDD, and PD but again was normal in Alzheimer disease patients. Compared with PD patients, in whom the putamen

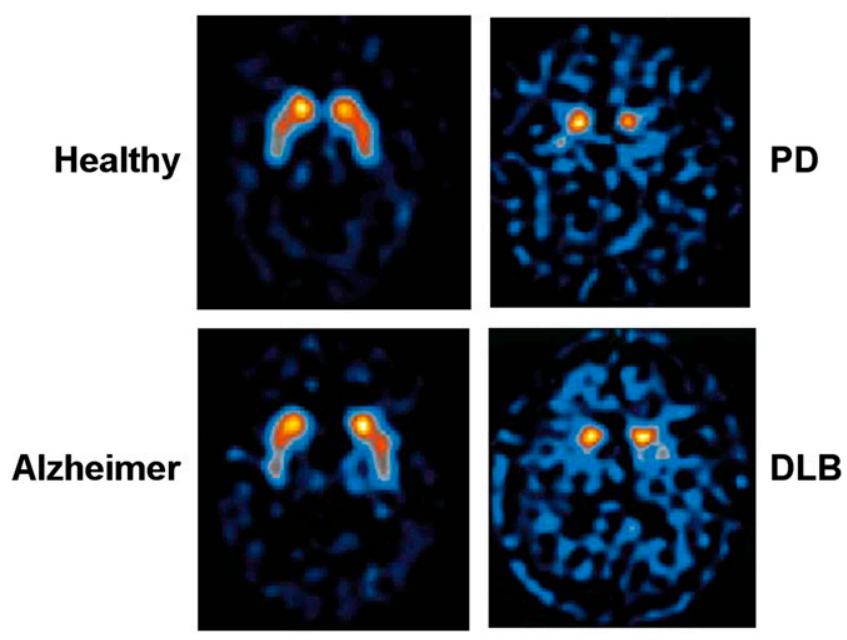

FIGURE 6. FP-CIT SPECT images of healthy subject and PD, Alzheimer, and DLB patients. Striatal DAT binding is reduced in PD and DLB patients. (Reprinted with permission of (98).) 
is selectively targeted resulting in a caudate-putamen gradient of DAT binding loss, patients with DLB and PDD showed a more uniform striatal reduction in ${ }^{123} \mathrm{I}-$ FP-CIT binding, with a reduced caudate-putamen gradient. There was a significant correlation between the Mini Mental State Examination scores and ${ }^{123}$ I-FP-CIT binding in PDD, supporting the hypothesis that striatal dopaminergic loss contributes to the cognitive impairment of these patients.

The role of mesofrontal dopaminergic projections in PD with dementia has been investigated with ${ }^{18} \mathrm{~F}$-dopa PET using statistical parametric mapping to localize significant reductions in dopamine storage capacity at a voxel level. When PD patients with and without dementia were matched for age, disease duration, and disease severity, interrogation of their ${ }^{18} \mathrm{~F}$-dopa uptake images with statistical parametric mapping localized a reduced capacity for putamen dopamine storage in both groups. However, compared with the PD patients, the PDD patients showed additional reductions in ${ }^{18} \mathrm{~F}$-dopa uptake in the right caudate and bilaterally in the ventral striatum and the anterior cingulate (102). These findings support the concept that dementia in PD is associated with impaired frontal and caudate dopaminergic function. Reduced frontal ${ }^{18} \mathrm{~F}$-dopa uptake has been previously reported in PD patients who showed impaired performance on tests of verbal fluency, verbal recall, and digit span (103).

\section{Cholinergic Function}

${ }^{123}$ I-iodobenzovesamicol SPECT is a marker of acetylcholine vesicle transporter binding in cholinergic nerve terminals. Reduced binding of ${ }^{123}$ I-iodobenzovesamicol has been reported in the parietal and occipital cortex of nondemented PD patients, and this reduction spreads to involve all cortical areas in PD patients with dementia (104). Another biomarker of cholinergic integrity is levels of acetylcholinesterase activity. This can be assessed with $N-{ }^{11} \mathrm{C}$-methylpiperidin-4-yl acetate $\left({ }^{11} \mathrm{C}-\mathrm{MP} 4 \mathrm{~A}\right)$ or $1-{ }^{11} \mathrm{C}$ methylpiperidin-4-yl propionate ( ${ }^{11} \mathrm{C}$-PMP) PET, and cortical binding of the former tracer has been reported to be reduced by $11 \%$ in PD and by $30 \%$ in PDD (105). Levels of cortical $N-{ }^{11} \mathrm{C}$-methylpiperidin-4-yl acetate binding correlated with levels of striatal ${ }^{18} \mathrm{~F}$-dopa uptake in a combined group of PD patients with and without dementia, suggesting that there is a parallel reduction in dopaminergic and cholinergic function in PD. $1{ }^{11} \mathrm{C}$-methylpiperidin-4-yl propionate $\mathrm{PET}$ has revealed a significant correlation between cortical acetylcholinesterase activity and performance on tests of attention in a combined group of PD and PDD patients (106). Interestingly, cortical acetylcholinesterase deficiency did not correlate with motor symptoms. Taken together, these findings suggest that a deficiency of cholinergic transmission contributes toward the dementia of PD and lends support to the therapeutic use of cholinesterase inhibitors.
The effect of cholinesterase inhibitor therapy on cerebral glucose metabolism has been assessed in 12 PDD patients (107). Cholinesterase inhibitor treatment improved memory and induced significant increases in cerebral metabolism in the left angular gyrus (extending to the supramarginal area and left superior and middle gyri), the right superior gyrus, and the left middle orbitofrontal gyrus. There were significant correlations between improvements in Mini Mental State Examination scores and increased cerebral metabolism in the left supramarginal, orbitofrontal, and cingulate areas.

\section{Measuring $\beta$-Amyloid Load in PD Dementia}

Pittsburgh compound B (PIB) is a neutral thioflavin that shows nanomolar affinity for fibrillar $\beta$-amyloid plaques in Alzheimer brain slices but low affinity for intracellular neurofibrillary tangles and Lewy bodies (108). ${ }^{11} \mathrm{C}-\mathrm{PIB}$ PET studies have reported 2-fold increases in tracer retention in the association cortex and cingulate of patients with Alzheimer disease, compared with healthy controls (109,110). ${ }^{11} \mathrm{C}-\mathrm{PIB}$ PET has been used to determine the prevalence of a raised amyloid load in DLB and PDD (Fig. 7) (111). Eleven of 13 DLB patients but only 2 of 13 PDD patients had significantly raised cortical amyloid levels. These findings suggest that $\beta$-amyloid deposition does not contribute significantly to the pathogenesis of PDD, in line with pathologic reports (112). Conversely, in DLB, in which the dementia precedes or coincides with parkinsonism, an increase in ${ }^{11} \mathrm{C}$-PIB uptake is seen in most patients (113). It has been concluded that the presence of amyloid accelerates dementia in PD but does not appear to influence the nature of the symptomatology (114).

In summary, dementia in PD is multifactorial, being associated with cortical Lewy body disease, amyloid deposition, and loss of dopaminergic and cortical cholinergic transmission. Functional imaging can help determine the relative contributions of these factors in individual patients and potentially rationalize the use of antiamyloid strategies.

\section{NEUROINFLAMMATION AND PD}

Microglia constitute $10 \%-20 \%$ of white cells in the brain and are normally in a resting state. A change in brain milieu, such as that induced by injury or degeneration, causes them to become activated and release cytokines (115). The mitochondria of activated microglia express translocator protein, previously known as the peripheral benzodiazepine receptor. This can be detected with a variety of PET ligands including the isoquinoline ${ }^{11} \mathrm{C}-\mathrm{PK} 11195$ (116).

Loss of substantia nigra neurons in PD has been shown to be associated with microglial activation (117). More recently, histochemical studies have shown that microglial activation in end-stage PD is widespread, being seen in the basal ganglia, cingulate, hippocampus, and cortical association areas (118). ${ }^{11} \mathrm{C}$-PK11195 PET has been used to study microglial activation in PD. Increased midbrain signal can 
FIGURE 7. ${ }^{11} \mathrm{C}$-PIB PET images of $\beta$-amyloid plaque load. Elderly healthy subject and PDD patient show no significant plaque deposition in brain, compared with 2 DLB patients, in whom amyloid deposition is extensive. (Courtesy of Paul Edison.)

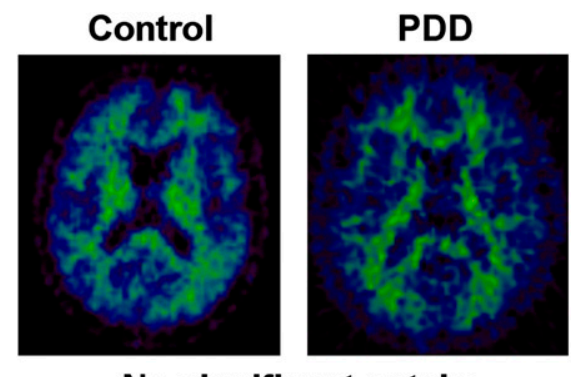

No significant uptake
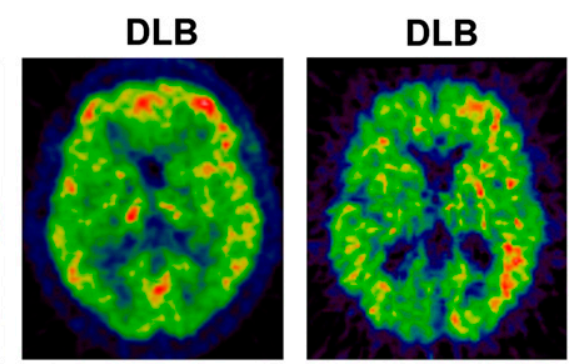

Increased uptake be detected, and this has been reported to correlate inversely with levels of posterior putamen ${ }^{11} \mathrm{C}$-CFT uptake, a PET marker of DAT binding (119). Increased ${ }^{11} \mathrm{C}$ PK11195 uptake has also been reported in the medulla and pons, striatum, pallidum, and frontal cortex in PD (120), in line with the known distribution of Lewy body pathology (Fig. 8) (121). Over a 2-y follow-up period, little change in the level of microglial activation was seen in PD although all patients deteriorated clinically. This observation could imply that microglial activation is merely an epiphenomenon in PD; however, postmortem studies have shown that these cells continue to express cytokine messenger RNA, suggesting that they could be driving disease progression while their population remains static.

\section{IMAGING CARDIAC SYMPATHETIC DENERVATION IN PD}

Several SPECT and PET studies have reported that most patients with idiopathic PD show a significant loss of sympathetic innervation of the heart whereas this is not a feature of atypical variants such as multiple-system atrophy (122-124). Decreased myocardial uptake of the sympathetic markers ${ }^{123}$ I-metaiodobenzylguanidine (MIBG) and ${ }^{18} \mathrm{~F}$-fluorodopamine has been reported in PD patients even at early stages of the disease when cardiovascular reflexes are still intact. However, ${ }^{123}$ I-MIBG SPECT is not
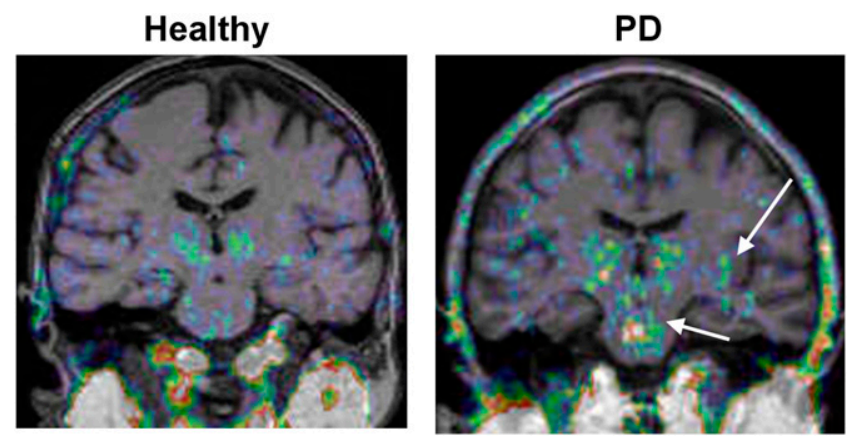

FIGURE 8. ${ }^{11} \mathrm{C}-\mathrm{PK} 11195$ PET scans of healthy subject and PD patient. Mild microglial activation is seen in thalamus of healthy control, whereas significantly raised activation is evident in midbrain and striata of PD patient. (Courtesy of Alex Gerhard.) a sensitive marker of early PD, as up to $50 \%$ of Hoehn and Yahr stage 1 patients can still show normal tracer binding (124). Both ${ }^{18} \mathrm{~F}$-dopamine and ${ }^{123} \mathrm{I}-\mathrm{MIBG}$ use the same metabolic pathway as norepinephrine, and their myocardial uptake reflects not only the density of postganglionic sympathetic neurons but also their functional integrity.

It has been suggested that cardiac sympathetic denervation contributes to symptoms of autonomic failure such as orthostatic hypotension. Oka et al. (125) examined the association between myocardial ${ }^{123}$ I-MIBG uptake and orthostatic hypotension, pulse, and blood pressure changes during the Valsalva maneuver and erect and supine plasma norepinephrine concentrations in PD patients. Mean myocardial ${ }^{123}$ I-MIBG uptake was significantly lower in PD patients with orthostatic hypotension and an abnormal Valsalva response. However, no association was found between the fall in systolic blood pressure on head-up tilt and baroreflex sensitivity or plasma norepinephrine concentrations. These results indicate that cardiac sympathetic dysfunction is a primary cause of impaired cardiovascular reflexes in $\mathrm{PD}$.

\section{CONCLUSION}

Structural changes in PD nigra can be detected with both transcranial sonography and diffusion tensor MRI. Rather than reflecting the severity of disease, transcranial sonography reveals a susceptibility to PD but can valuably support the diagnosis. PET and SPECT measurements of dopamine terminal function sensitively detect dopamine deficiency in both symptomatic and at-risk subjects for parkinsonian syndromes. Measures of striatal dopamine deficiency correlate with bradykinesia and rigidity and potentially provide biomarkers for monitoring disease progression. Normal striatal DAT binding in a patient suspected of having PD excludes a dopamine deficiency syndrome and is associated with a good prognosis. Atypical parkinsonian syndromes can be sensitively discriminated from PD with either diffusion-weighted MRI or ${ }^{18} \mathrm{~F}-\mathrm{FDG}$ PET.

DLB can be reliably discriminated from Alzheimer disease by the presence of reduced striatal DAT binding. Most DLB patients show a significant amyloid load with ${ }^{11} \mathrm{C}$-PIB PET, whereas this finding is less common in PDD patients. 
Extensive microglial activation can be detected in PD with the translocator protein marker ${ }^{11} \mathrm{C}-\mathrm{PK} 11195$ PET, providing a rationale for exploring the use of antiinflammatory agents as potential neuroprotectants.

\section{REFERENCES}

1. Hughes AJ, Daniel SE, Lees AJ. Improved accuracy of clinical diagnosis of Lewy body Parkinson's disease. Neurology. 2001;57:1497-1499.

2. Schneider SA, Edwards MJ, Mir P, et al. Patients with adult-onset dystonic tremor resembling parkinsonian tremor have scans without evidence of dopaminergic deficit (SWEDDs). Mov Disord. 2007;22:2210-2215.

3. Fahn S. Parkinson disease, the effect of levodopa, and the ELLDOPA trial. Arch Neurol. 1999;56:529-535.

4. Whone AL, Watts RL, Stoessl J, et al. Slower progression of PD with ropinirole versus L-dopa: the REAL-PET study. Ann Neurol. 2003;54:93-101.

5. Geng DY, Li YX, Zee CS. Magnetic resonance imaging-based volumetric analysis of basal ganglia nuclei and substantia nigra in patients with Parkinson's disease. Neurosurgery. 2006;58:256-262.

6. Hutchinson M, Raff U. Structural changes of the substantia nigra in Parkinson's disease as revealed by MR imaging. Am J Neuroradiol. 2000;21:697-701.

7. Hu MT, White SJ, Herlihy AH, Chaudhuri KR, Hajnal JV, Brooks DJ. A comparison of ${ }^{18} \mathrm{~F}$-dopa PET and inversion recovery MRI in the diagnosis of Parkinson's disease. Neurology. 2001;56:1195-1200.

8. Minati L, Grisoli M, Carella F, De Simone T, Bruzzone MG, Savoiardo M. Imaging degeneration of the substantia nigra in Parkinson disease with inversion-recovery MR imaging. Am J Neuroradiol. 2007;28:309-313.

9. Michaeli S, Oz G, Sorce DJ, et al. Assessment of brain iron and neuronal integrity in patients with Parkinson's disease using novel MRI contrasts. Mov Disord. 2007;22:334-340.

10. Vaillancourt DE, Spraker MB, Prodoehl J, et al. High-resolution diffusion tensor imaging in the substantia nigra of de novo Parkinson disease. Neurology. 2009; 72:1378-1384.

11. Berg D, Siefker C, Becker G. Echogenicity of the substantia nigra in Parkinson's disease and its relation to clinical findings. J Neurol. 2001;248: 684-689.

12. Berg D, Merz B, Reiners K, Naumann M, Becker G. Five-year follow-up study of hyperechogenicity of the substantia nigra in Parkinson's disease. Mov Disord. 2005;20:383-385.

13. Berg D, Roggendorf W, Schroder U, et al. Echogenicity of the substantia nigra: association with increased iron content and marker for susceptibility to nigrostriatal injury. Arch Neurol. 2002;59:999-1005.

14. Walter U, Klein C, Hilker R, Benecke R, Pramstaller PP, Dressler D. Brain parenchyma sonography detects preclinical parkinsonism. Mov Disord. 2004;19:1445-1449.

15. Schweitzer KJ, Brussel T, Leitner $P$, et al. Transcranial ultrasound in different monogenetic subtypes of Parkinson's disease. J Neurol. 2007;254:613616.

16. Gaenslen A, Unmuth B, Godau J, et al. The specificity and sensitivity of transcranial ultrasound in the differential diagnosis of Parkinson's disease: a prospective blinded study. Lancet Neurol. 2008;7:417-424.

17. Vlaar AM, de Nijs T, van Kroonenburgh MJ, et al. The predictive value of transcranial duplex sonography for the clinical diagnosis in undiagnosed parkinsonian syndromes: comparison with SPECT scans. BMC Neurol. 2008;8:42.

18. Stockner H, Sojer M, K KS, et al. Midbrain sonography in patients with essential tremor. Mov Disord. 2007;22:414-417.

19. Walter U, Hoeppner J, Prudente-Morrissey L, Horowski S, Herpertz SC, Benecke R. Parkinson's disease-like midbrain sonography abnormalities are frequent in depressive disorders. Brain. 2007;130:1799-1807.

20. Schulz JB, Skalej M, Wedekind D, et al. Magnetic resonance imaging-based volumetry differentiates idiopathic Parkinson's syndrome from multiple system atrophy and progressive supranuclear palsy. Ann Neurol. 1999;45:65-74.

21. Paviour DC, Price SL, Jahanshahi M, Lees AJ, Fox NC. Regional brain volumes distinguish PSP, MSA-P, and PD: MRI-based clinico-radiological correlations. Mov Disord. 2006;21:989-996.

22. Schocke MF, Seppi K, Esterhammer R, et al. Diffusion-weighted MRI differentiates the Parkinson variant of multiple system atrophy from PD. Neurology. 2002;58:575-580.

23. Seppi K, Schocke MF, Esterhammer R, et al. Diffusion-weighted imaging discriminates progressive supranuclear palsy from PD, but not from the
Parkinson variant of multiple system atrophy. Neurology. 2003;60:922927.

24. Nicoletti G, Lodi R, Condino F, et al. Apparent diffusion coefficient measurements of the middle cerebellar peduncle differentiate the Parkinson variant of MSA from Parkinson's disease and progressive supranuclear palsy. Brain. 2006;129:2679-2687.

25. Paviour DC, Thornton JS, Lees AJ, Jager HR. Diffusion-weighted magnetic resonance imaging differentiates Parkinsonian variant of multiple-system atrophy from progressive supranuclear palsy. Mov Disord. 2007;22:68-74.

26. Walter U, Dressler D, Probst T, et al. Transcranial brain sonography findings in discriminating between parkinsonism and idiopathic Parkinson disease. Arch Neurol. 2007;64:1635-1640.

27. Brooks DJ, Frey KA, Marek KL, et al. Assessment of neuroimaging techniques as biomarkers of the progression of Parkinson's disease. Exp Neurol. 2003; 184(suppl):S68-S79.

28. Sawle GV, Playford ED, Brooks DJ, Quinn N, Frackowiak RSJ. Asymmetrical presynaptic and postsynaptic changes in the striatal dopamine projection in dopa-naive parkinsonism: diagnostic implications of the D2 receptor status. Brain. 1993;116:853-867.

29. Marek KL, Seibyl JP, Zoghbi SS, et al. [I-123] beta-CIT SPECT imaging demonstrates bilateral loss of dopamine transporters in hemi-Parkinson's disease. Neurology. 1996;46:231-237.

30. Morrish PK, Sawle GV, Brooks DJ. Clinical and $\left[{ }^{18} \mathrm{~F}\right]$ dopa PET findings in early Parkinson's disease. J Neurol Neurosurg Psychiatry. 1995;59:597-600.

31. Marek K, Innis R, van Dyck C, et al. [ $\left.{ }^{123} \mathrm{I}\right]$ beta-CIT SPECT imaging assessment of the rate of Parkinson's disease progression. Neurology. 2001;57:2089-2094.

32. Vingerhoets FJG, Schulzer M, Calne DB, Snow BJ. Which clinical sign of Parkinson's disease best reflects the nigrostriatal lesion? Ann Neurol. 1997; 41:58-64.

33. Benamer HTS, Patterson J, Wyper DJ, Hadley DM, Macphee GJA, Grosset DG. Correlation of Parkinson's disease severity and duration with I-123-FP-CIT SPECT striatal uptake. Mov Disord. 2000;15:692-698.

34. Seibyl JP, Marek KL, Quinlan D, et al. Decreased single-photon emission computed tomographic $\left[{ }^{123} \mathrm{I}\right] \mathrm{b}$-CIT striatal uptake correlates with symptom severity in Parkinson's disease. Ann Neurol. 1995;38:589-598.

35. Whone AL, Moore RY, Piccini P, Brooks DJ. Plasticity in the nigropallidal pathway in Parkinson's disease: an ${ }^{18}$ F-dopa PET study. Ann Neurol. 2003; 53:206-213.

36. Benamer TS, Patterson J, Grosset DG, et al. Accurate differentiation of parkinsonism and essential tremor using visual assessment of $\left[{ }^{123} \mathrm{I}\right]$-FP-CIT imaging: The [ $\left.{ }^{123} \mathrm{I}\right]$-FP-CIT Study Group. Mov Disord. 2000;15:503-510.

37. Jennings DL, Seibyl JP, Oakes D, Eberly S, Murphy J, Marek K. $\left({ }^{123}\right.$ I) beta-CIT and single-photon emission computed tomographic imaging vs clinical evaluation in Parkinsonian syndrome: unmasking an early diagnosis. Arch Neurol. 2004;61:1224-1229.

38. Marshall VL, Reininger CB, Marquardt M, et al. Parkinson's disease is overdiagnosed clinically at baseline in diagnostically uncertain cases: a 3-year European multicenter study with repeat [ ${ }^{123}$ I]FP-CIT SPECT. Mov Disord. 2009;24:500-508.

39. Catafau AM, Tolosa E. Impact of dopamine transporter SPECT using ${ }^{123}$ IIoflupane on diagnosis and management of patients with clinically uncertain Parkinsonian syndromes. Mov Disord. 2004;19:1175-1182.

40. Tolosa E, Borght TV, Moreno E. Accuracy of DaTSCAN ( ${ }^{123}$ I-Ioflupane) SPECT in diagnosis of patients with clinically uncertain parkinsonism: 2-year follow-up of an open-label study. Mov Disord. 2007;22:2346-2351.

41. Marshall VL, Patterson J, Hadley DM, Grosset KA, Grosset DG. Two-year followup in 150 consecutive cases with normal dopamine transporter imaging. Nucl Med Commun. 2006;27:933-937.

42. Marshall VL, Patterson J, Hadley DM, Grosset KA, Grosset DG. Successful antiparkinsonian medication withdrawal in patients with parkinsonism and normal FP-CIT SPECT. Mov Disord. 2006;21:2247-2250.

43. Brooks DJ. Functional imaging in relation to parkinsonian syndromes. J Neurol Sci. 1993;115:1-17.

44. Eidelberg D, Moeller JR, Dhawan V, et al. The metabolic topography of parkinsonism. J Cereb Blood Flow Metab. 1994;14:783-801.

45. Su PC, Ma Y, Fukuda M, et al. Metabolic changes following subthalamotomy for advanced Parkinson's disease. Ann Neurol. 2001;50:514-520.

46. Feigin A, Fukuda M, Dhawan V, et al. Metabolic correlates of levodopa response in Parkinson's disease. Neurology. 2001;57:2083-2088.

47. Eckert T, Feigin A, Lewis DE, Dhawan V, Frucht S, Eidelberg D. Regional metabolic changes in parkinsonian patients with normal dopaminergic imaging. Mov Disord. 2007;22:167-173.

48. Burn DJ, Sawle GV, Brooks DJ. The differential diagnosis of Parkinson's disease, multiple system atrophy, and Steele-Richardson-Olszewski syndrome: 
discriminant analysis of striatal ${ }^{18}$ F-dopa PET data. J Neurol Neurosurg Psychiatry. 1994;57:278-284.

49. Pirker W, Asenbaum S, Bencsits G, et al. [I-123]beta-CIT SPECT in multiple system atrophy, progressive supranuclear palsy, and corticobasal degeneration. Mov Disord. 2000;15:1158-1167.

50. Messa C, Volonte MA, Fazio F, et al. Differential distribution of striatal $\left[{ }^{123} \mathrm{I}\right] \mathrm{b}-\mathrm{CIT}$ in Parkinson's disease and progressive supranuclear palsy, evaluated with single-photon emission tomography. Eur J Nucl Med. 1998; 25:1270-1276.

51. Sawle GV, Brooks DJ, Marsden CD, Frackowiak RSJ. Corticobasal degeneration: a unique pattern of regional cortical oxygen metabolism and striatal fluorodopa uptake demonstrated by positron emission tomography. Brain. 1991;114:541-556.

52. Eidelberg D, Takikawa S, Moeller JR, et al. Striatal hypometabolism distinguishes striatonigral degeneration from Parkinson's disease. Ann Neurol. 1993;33:518-527.

53. Eidelberg D, Dhawan V, Moeller JR, et al. The metabolic landscape of corticobasal ganglionic degeneration: regional asymmetries studied with positron emission tomography. J Neurol Neurosurg Psychiatry. 1991;54:856-862.

54. Eckert T, Barnes A, Dhawan V, et al. FDG PET in the differential diagnosis of parkinsonian disorders. Neuroimage. 2005;26:912-921.

55. Golbe LI. The genetics of Parkinson's disease: a reconsideration. Neurology. 1990;40(suppl 3):7-16.

56. Piccini P, Morrish PK, Turjanski N, et al. Dopaminergic function in familial Parkinson's disease: a clinical and ${ }^{18}$ F-dopa PET study. Ann Neurol. 1997; 41:222-229.

57. Hilker R, Klein C, Hedrich K, et al. The striatal dopaminergic deficit is dependent on the number of mutant alleles in a family with mutations in the parkin gene: evidence for enzymatic parkin function in humans. Neurosci Lett. 2002;323:50-54.

58. Khan NL, Brooks DJ, Pavese N, et al. Progression of nigrostriatal dysfunction in a parkin kindred: an $\left[{ }^{18} \mathrm{~F}\right]$ dopa PET and clinical study. Brain. 2002;125:2248-2256.

59. Scherfler C, Khan NL, Pavese N, et al. Striatal and cortical pre- and postsynaptic dopaminergic dysfunction in sporadic parkin-linked parkinsonism. Brain. 2004;127:1332-1342.

60. Khan NL, Scherfler C, Graham E, et al. Dopaminergic dysfunction in unrelated, asymptomatic carriers of a single parkin mutation. Neurology. 2005;64:134136.

61. Adams JR, van Netten H, Schulzer M, et al. PET in LRRK2 mutations: comparison to sporadic Parkinson's disease and evidence for presymptomatic compensation. Brain. 2005;128:2777-2785.

62. Lee CS, Samii A, Sossi V, et al. In vivo positron emission tomographic evidence for compensatory changes in presynaptic dopaminergic nerve terminals in Parkinson's disease. Ann Neurol. 2000;47:493-503.

63. Ponsen MM, Stoffers D, Booij J, Van Eck-Smit BL, Wolters E, Berendse HW. Idiopathic hyposmia as a preclinical sign of Parkinson's disease. Ann Neurol. 2004;56:173-181.

64. Eisensehr I, Linke R, Noachtar S, Schwarz J, Gildehaus FJ, Tatsch K. Reduced striatal dopamine transporters in idiopathic rapid eye movement sleep behaviour disorder: comparison with Parkinson's disease and controls. Brain. 2000;123:1155-1160.

65. Stiasny-Kolster K, Doerr Y, Moller JC, et al. Combination of 'idiopathic' REM sleep behaviour disorder and olfactory dysfunction as possible indicator for alpha-synucleinopathy demonstrated by dopamine transporter FP-CIT-SPECT. Brain. 2005;128:126-137.

66. Sommer U, Hummel T, Cormann K, et al. Detection of presymptomatic Parkinson's disease: combining smell tests, transcranial sonography, and SPECT. Mov Disord. 2004;19:1196-1202.

67. Spiegel J, Hellwig D, Mollers MO, et al. Transcranial sonography and [123I]FPCIT SPECT disclose complementary aspects of Parkinson's disease. Brain. 2006;129:1188-1193.

68. de la Fuente-Fernández R, Pal PK, Vingerhoets FJG, et al. Evidence for impaired presynaptic dopamine function in parkinsonian patients with motor fluctuations. J Neural Transm. 2000;107:49-57.

69. Playford ED, Brooks DJ. In vivo and in vitro studies of the dopaminergic system in movement disorders. Cerebrovasc Brain Metab Rev. 1992;4:144-171.

70. Antonini A, Schwarz J, Oertel WH, Beer HF, Madeja UD, Leenders KL. $\left[{ }^{11} \mathrm{C}\right]$ raclopride and positron emission tomography in previously untreated patients with Parkinson's disease: influence of L-dopa and lisuride therapy on striatal dopamine D2-receptors. Neurology. 1994;44:1325-1329.

71. Turjanski N, Lees AJ, Brooks DJ. PET studies on striatal dopaminergic receptor binding in drug naive and L-dopa treated Parkinson's disease patients with and without dyskinesia. Neurology. 1997;49:717-723.
72. Laruelle M. Imaging synaptic neurotransmission with in vivo binding competition techniques: a critical review. J Cereb Blood Flow Metab. 2000;20: 423-451.

73. Breier A, Su TP, Saunders R, et al. Schizophrenia is associated with elevated amphetamine-induced synaptic dopamine concentrations: evidence from novel positron emission tomography method. Proc Natl Acad Sci USA. 1997;94: 2569-2574.

74. Pavese N, Evans AH, Tai YF, et al. Clinical correlates of levodopa-induced dopamine release in Parkinson disease: a PET study. Neurology. 2006;67:16121617.

75. Torstenson R, Hartvig P, Långström B, Westerberg G, Tedroff J. Differential effects of levodopa on dopaminergic function in early and advanced Parkinson's disease. Ann Neurol. 1997;41:334-340.

76. De la Fuente-Fernandez R, Lu JQ, Sossi V, et al. Biochemical variations in the synaptic level of dopamine precede motor fluctuations in Parkinson's disease: PET evidence of increased dopamine turnover. Ann Neurol. 2001;49:298-303.

77. Brotchie JM. Advances in understanding the neural mechanisms underlying L-DOPA-induced dyskinesia. Adv Neurol. 1999;80:71-85.

78. Piccini P, Weeks RA, Brooks DJ. Opioid receptor binding in Parkinson's patients with and without levodopa-induced dyskinesias. Ann Neurol. 1997;42:720-726.

79. Whone AL, Rabiner EA, Arahata Y, Luthra SK, Hargreaves R, Brooks DJ. Reduced substance $\mathrm{P}$ binding in Parkinson's disease complicated by dyskinesias: an F-18-L829165 PET study [abstract]. Neurology. 2002;58(suppl 3):A488-A489.

80. Burn DJ. Beyond the iron mask: towards better recognition and treatment of depression associated with Parkinson's disease. Mov Disord. 2002;17:445-454.

81. Agid Y, Ruberg M, Raisman R, Hirsch E, Javoy-Agid F. The biochemistry of Parkinson's disease. In: Stern GM, ed. Parkinson's Disease. London, U.K.: Chapman and Hall Medical; 1990:99-125.

82. Laruelle M, Baldwin RM, Malison RT, et al. SPECT imaging of dopamine and serotonin transporters with $\left[{ }^{123} \mathrm{I}\right]$ beta-CIT: pharmacological characterization of brain uptake in nonhuman primates. Synapse. 1993;13:295-309.

83. Kim SE, Choi JY, Choe YS, Choi Y, Lee WY. Serotonin transporters in the midbrain of Parkinson's disease patients: a study with ${ }^{123}$ I-beta-CIT SPECT. J Nucl Med. 2003;44:870-876.

84. Doder M, Rabiner EA, Turjanski N, Lees AJ, Brooks DJ. Brain serotonin HT1A receptors in Parkinson's disease with and without depression measured by positron emission tomography and ${ }^{11} \mathrm{C}$-WAY 100635 [abstract]. Mov Disord. 2000; 15 (suppl 3):213.

85. Remy P, Doder M, Lees AJ, Turjanski N, Brooks DJ. Depression in Parkinson's disease: loss of dopamine and noradrenaline innervation in the limbic system. Brain. 2005;128:1314-1322.

86. Cilia R, Siri C, Marotta G, et al. Functional abnormalities underlying pathological gambling in Parkinson disease. Arch Neurol. 2008;65:1604-1611.

87. Steeves TD, Miyasaki J, Zurowski M, et al. Increased striatal dopamine release in parkinsonian patients with pathological gambling: a $\left[{ }^{11} \mathrm{C}\right]$ raclopride PET study. Brain. 2009; 132:1376-1385.

88. Emre M. Dementia associated with Parkinson's disease. Lancet Neurol. 2003;2:229-237.

89. Hely MA, Reid WG, Adena MA, Halliday GM, Morris JG. The Sydney multicenter study of Parkinson's disease: the inevitability of dementia at 20 years. Mov Disord. 2008;23:837-844.

90. Summerfield C, Junque C, Tolosa E, et al. Structural brain changes in Parkinson disease with dementia: a voxel-based morphometry study. Arch Neurol. 2005;62:281-285.

91. Ramirez-Ruiz B, Marti MJ, Tolosa E, et al. Longitudinal evaluation of cerebral morphological changes in Parkinson's disease with and without dementia. $J$ Neurol. 2005;252:1345-1352.

92. Burton EJ, McKeith IG, Burn DJ, O’Brien JT. Brain atrophy rates in Parkinson's disease with and without dementia using serial magnetic resonance imaging. Mov Disord. 2005;20:1571-1576.

93. Peppard RF, Martin WRW, Carr GD, et al. Cerebral glucose metabolism in Parkinson's-disease with and without dementia. Arch Neurol. 1992;49:1262-1268.

94. Vander-Borght T, Minoshima S, Giordani B, et al. Cerebral metabolic differences in Parkinson's and Alzheimer's disease matched for dementia severity. J Nucl Med. 1997;38:797-802.

95. Hoffman JM, Welsh-Bohmer KA, Hanson M, et al. FDG PET imaging in patients with pathologically verified dementia. J Nucl Med. 2000;41:1920-1928.

96. Hu MTM, Taylor-Robinson SD, Chaudhuri KR, et al. Cortical dysfunction in non-demented Parkinson's disease patients: a combined ${ }^{31}$ phosphorus MRS and ${ }^{18}$ FDG PET study. Brain. 2000;123:340-352.

97. Albin RL, Minoshima S, D'Amato CJ, Frey KA, Kuhl DA, Sima AA. Fluorodeoxyglucose positron emission tomography in diffuse Lewy body disease. Neurology. 1996;47:462-466. 
98. Walker Z, Costa DC, Walker RW, et al. Differentiation of dementia with Lewy bodies from Alzheimer's disease using a dopaminergic presynaptic ligand. J Neurol Neurosurg Psychiatry. 2002;73:134-140.

99. Walker Z, Jaros E, Walker RW, et al. Dementia with Lewy bodies: a comparison of clinical diagnosis, FP-CIT SPECT imaging and autopsy. J Neurol Neurosurg Psychiatry. 2007;78:1176-1181.

100. O'Brien JT, McKeith IG, Walker Z, et al. Diagnostic accuracy of ${ }^{123}$ I-FP-CIT SPECT in possible dementia with Lewy bodies. Br J Psychiatry. 2009;194: 34-39.

101. O'Brien JT, Colloby S, Fenwick J, et al. Dopamine transporter loss visualized with FP-CIT SPECT in the differential diagnosis of dementia with Lewy bodies. Arch Neurol. 2004;61:919-925.

102. Ito K, Nagano-Saito A, Kato T, et al. Striatal and extrastriatal dysfunction in Parkinson's disease with dementia: a 6-[ $\left.{ }^{18} \mathrm{~F}\right]$ fluoro-L-dopa PET study. Brain. 2002; 125:1358-1365.

103. Rinne JO, Portin R, Ruottinen H, et al. Cognitive impairment and the brain dopaminergic system in Parkinson disease: $\left[{ }^{18} \mathrm{~F}\right]$ fluorodopa positron emission tomographic study. Arch Neurol. 2000;57:470-475.

104. Kuhl DE, Minoshima S, Fessler JA, et al. In vivo mapping of cholinergic terminals in normal aging, Alzheimer's disease, and Parkinson's disease. Ann Neurol. 1996;40:399-410.

105. Hilker R, Thomas AV, Klein JC, et al. Dementia in Parkinson disease: functional imaging of cholinergic and dopaminergic pathways. Neurology. 2005;65:1716-1722.

106. Bohnen NI, Kaufer DI, Hendrickson R, et al. Cognitive correlates of cortical cholinergic denervation in Parkinson's disease and parkinsonian dementia. $J$ Neurol. 2006;253:242-247.

107. Lee PH, Yong SW, An YS. Changes in cerebral glucose metabolism in patients with Parkinson disease with dementia after cholinesterase inhibitor therapy. $J$ Nucl Med. 2008;49:2006-2011.

108. Bacskai BJ, Frosch MP, Freeman SH, et al. Molecular imaging with Pittsburgh Compound B confirmed at autopsy: a case report. Arch Neurol. 2007;64:431434.

109. Klunk WE, Engler H, Nordberg A, et al. Imaging brain amyloid in Alzheimer's disease with Pittsburgh Compound-B. Ann Neurol. 2004;55:306-319.

110. Edison P, Archer HA, Hinz R, et al. Amyloid, hypometabolism, and cognition in Alzheimer disease: an $\left[{ }^{11} \mathrm{C}\right] \mathrm{PIB}$ and $\left[{ }^{18} \mathrm{~F}\right] \mathrm{FDG}$ PET study. Neurology. 2007;68:501-508.

111. Edison P, Rowe CC, Rinne JO, et al. Amyloid load in Parkinson's disease dementia and Lewy body dementia measured with $\left[{ }^{11} \mathrm{C}\right] \mathrm{PIB}$ positron emission tomography. J Neurol Neurosurg Psychiatry. 2008;79:1331-1338.
112. Aarsland D, Perry R, Brown A, Larsen JP, Ballard C. Neuropathology of dementia in Parkinson's disease: a prospective, community-based study. Ann Neurol. 2005;58:773-776.

113. Rowe CC, Ng S, Ackermann U, et al. Imaging beta-amyloid burden in aging and dementia. Neurology. 2007;68:1718-1725.

114. Gomperts SN, Rentz DM, Moran E, et al. Imaging amyloid deposition in Lewy body diseases. Neurology. 2008;71:903-910.

115. Kreutzberg GW. Microglia: a sensor for pathological events in the CNS. Trends Neurosci. 1996;19:312-318.

116. Doorduin J, de Vries EF, Dierckx RA, Klein HC. PET imaging of the peripheral benzodiazepine receptor: monitoring disease progression and therapy response in neurodegenerative disorders. Curr Pharm Des. 2008;14:3297-3315.

117. McGeer PL, Itagaki S, Boyes BE, McGeer EG. Reactive microglia are positive for HLA-DR in the substantia nigra of Parkinson's and Alzheimer's disease brains. Neurology. 1988;38:1285-1291.

118. Imamura K, Hishikawa N, Sawada M, Nagatsu T, Yoshida M, Hashizume Y. Distribution of major histocompatibility complex class II-positive microglia and cytokine profile of Parkinson's disease brains. Acta Neuropathol. 2003;106:518-526.

119. Ouchi Y, Yoshikawa E, Sekine Y, et al. Microglial activation and dopamine terminal loss in early Parkinson's disease. Ann Neurol. 2005;57:168-175.

120. Gerhard A, Pavese N, Hotton GR, et al. Microglial activation in Parkinson's disease: its longitudinal course and correlation with clinical parameters: an $\left[{ }^{11} \mathrm{C}\right](\mathrm{R})-\mathrm{PK} 11195$ PET study [abstract]. Neurology. 2004;62(suppl):A432.

121. Braak H, Tredici KD, Rub U, de Vos RA, Jansen Steur EN, Braak E. Staging of brain pathology related to sporadic Parkinson's disease. Neurobiol Aging. 2003;24:197-211.

122. Goldstein DS, Holmes C, Li ST, Bruce S, Metman LV, Cannon RO III. Cardiac sympathetic denervation in Parkinson disease. Ann Intern Med. 2000;133:338347.

123. Spiegel J, Mollers MO, Jost WH, et al. FP-CIT and MIBG scintigraphy in early Parkinson's disease. Mov Disord. 2005;20:552-561.

124. Takatsu H, Nagashima K, Murase M, et al. Differentiating Parkinson disease from multiple-system atrophy by measuring cardiac iodine-123 metaiodobenzylguanidine accumulation. JAMA. 2000;284:44-45.

125. Oka H, Yoshioka M, Onouchi K, et al. Characteristics of orthostatic hypotension in Parkinson's disease. Brain. 2007;130:2425-2432.

126. Vaillancourt DE, Spraker MB, Prodoehl J, et al. High-resolution diffusion tensor imaging in the substantia nigra of de novo Parkinson disease. Neurology. 2009;72:1378-1384. 